\title{
The Adsorption Properties of the Sorbents Based on Nanofibrous Carbon
}

\section{Hoang Kim Bong, Sergei Mikhalovich Pestov, Vitaly Rafaelovich Flid, Aida Raevna Karaeva, Boris Vladimirovich Peshnev}

Chemistry Department of the Scientific-Research Centre on “Adsorption and Surface Phenomena”, Moscow Technological University, Moscow, Russia

Email: vkb846@yandex.ru

How to cite this paper: Bong, H.K., Pestov, S.M., Flid, V.R., Karaeva, A.R. and Peshnev, B.V. (2017) The Adsorption Properties of the Sorbents Based on Nanofibrous Carbon. Open Journal of Applied Sciences, 7, 720-728.

https://doi.org/10.4236/ojapps.2017.712051

Received: December 6, 2017

Accepted: December 26, 2017

Published: December 29, 2017

Copyright ( 92017 by authors and Scientific Research Publishing Inc. This work is licensed under the Creative Commons Attribution International License (CC BY 4.0).

http://creativecommons.org/licenses/by/4.0/

\begin{abstract}
The results of research on the adsorption characteristics of materials based on fibrous carbon (CNF) are considered in this paper. It is shown that changing the conditions and procedure of CNF modifying namely specific adsorption surface, volume of the pore space, and parameters of the pore structure it became possible ultimately to vary in a wide range the adsorption characteristics of obtained materials.
\end{abstract}

\section{Keywords}

Carbon Nanotubes, Nanofibers, Carbon Monoxide, Fibrous Carbon, Adsorption, Adsorbents, Surface, Porosity, Modification, Demetallization, Filamentary Catalytic Carbon

\section{Introduction}

Carbon materials occupy a significant part in the range of highly porous materials. They find a vast application in different fields of science and technology as adsorbents for lightening technical oils, in water purification and gas blowouts, in production of drug substances for medical purposes, as well as for the adsorption of toxins from biological fluids or directly from blood. Carbon materials (CM) are often used as catalyst supports and adsorbents in chemical and petrochemical processes.

Carbon nanotubes (CNT) and nanofibres (NF) rank high among various carbon materials (CM) of high porosity. They are specific carbon varieties which appear to be coiled up graphite nets with the diameter as much as some nanometers. The material produced by means of thermocatalytic decomposition of carbon or carbon monoxide disproportionation on $\mathrm{Fe}, \mathrm{CO}, \mathrm{N}$ surfaces, known as 
fibrous carbon (FC) or filamentary catalytic carbon (FCC) etc. [1] [2], may also be related to as carbon nanofibres. An important characteristic of carbon fiber is its high adsorption capacity [3], one of the most promising directions to date being its use as a sorbent or catalyst support [4] [5] [6] [7].

\section{Experimental}

The adsorption effect of CNT and FC porous particles modified by demetallization-thermotreating (method (I) or thermo treating-demetallization (method (II) is presented in this paper. The method of modification of FC was given in detail earlier [8]. The ability of carbon materials to absorb gases and vapors of different materials was studied by statistic volumetric and mass methods. Gas chromatography methods (low temperature adsorption of nitrogen) and BET method (adsorption of benzene and acetic acid) were applied to determine the specific surface area of CM.

\section{Results and Discussion}

Depending on the conditions of treatment, the value of specific surface area (as to nitrogen) of CNF, after its demetallization through treatment with $37 \% \mathrm{HCl}$ solution, varied within $\sim 173-300 \mathrm{~m}^{2} \cdot \mathrm{g}^{-1} / \mathrm{g}$ and proved to be higher than the calculated values of adsorption surface $\left(\sim 139 \mathrm{~m}^{2} \cdot \mathrm{g}^{-1}\right)$. Earlier, it was suggested [8] [9], that due to the demetallization process of carbon materials formation of additional pores resulted, which in turn significantly increased the surface of CF.

While analyzing the image of the "body" of fiber made with the help of transmitted electron microscopy before and after the process of demetallization Figure 1, formation of additional pores was not detected. In Figure 1(a) one can see the metal only in the "head" of the fiber. Demetallization process having been performed, void repeating the form of the removed metal was observed in the head of the fiber.

Analysis of micrographs of CNF, taken before and after the process of demetallization, allowed us to determine the external $D$ and internal diameter $d$ of the fiber (Table 1). Comparison of diameters showed that as a result of demetallization, internal diameter of the fiber increased while internal one decreased.

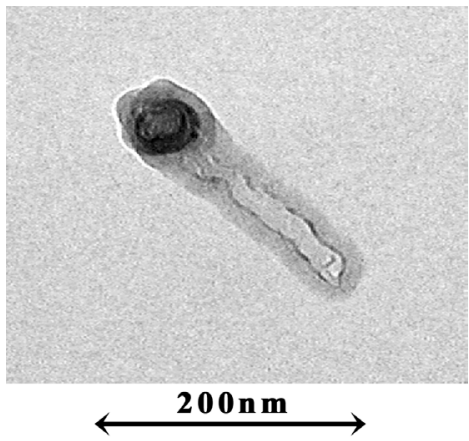

(a)

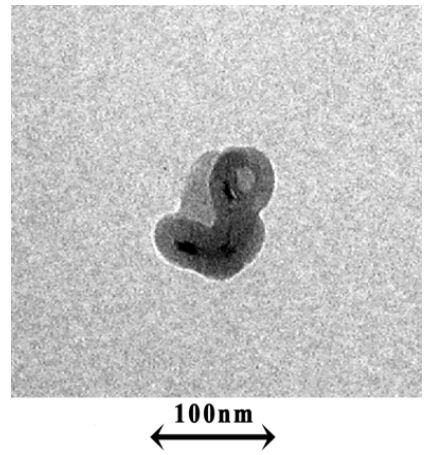

(b)

Figure 1. Micrograph of a CNF before (a) and after (b) of the process of demetallization. 
Table 1. FC and CNT features.

\begin{tabular}{cccccc}
\hline \multirow{2}{*}{ Sample } & \multicolumn{2}{c}{ Average diameter, $\mathrm{nm}$} & \multicolumn{2}{c}{ Specific surface, $\mathrm{m}^{2} \cdot \mathrm{g}^{-1}}$. \\
\cline { 2 - 5 } & Outer $(D)$ & Inner $(d)$ & Expected $\left(S_{s p}^{m}\right)$ & $\begin{array}{c}\text { Experimental } \\
\left(S_{s p}^{\prime}\right)\end{array}$ & $\Delta S\left(\mathrm{~m}^{2} \cdot \mathrm{g}^{-1}.\right)$ \\
\hline FC & 32.6 & 13.9 & 55.4 & 86.0 & 30.6 \\
CNT & 34.5 & 9.0 & 139.0 & 173.0 & 34.0 \\
\hline
\end{tabular}

Specific surface area was calculated from the results of electron microscopy, considering the average values of $D$ and $d$ by the formula:

$$
S_{s p}^{m}=\frac{S}{m}=\frac{4(d+D)}{\rho\left(D^{2}-d^{2}\right)}=\frac{4}{\rho(D-d)}
$$

assuming that the length of carbon fiber significantly exceeds its diameter $(L \gg D)$. Results of the calculation are shown in Table 1. Close values of SSA may serve as basis to assume the roughness of carbon fibers surface.

X-ray diffraction showed that the size of CNF graphite crystallite (L) compared with the initial material decreased from 53 to $3.18 \AA$ A, while interplanar distance between hexane grids increased from $3.394 \mathrm{~A}$ to $3.423 \AA$ Á. It is evident that this effect is due to the embedding of iron and hydrogen chlorides formed as a result of the process of demetallization into the interplanar distance of crystal lattice of graphite layers.

Additional results were obtained from analyses of benzene and acetic acid vapor adsorption isotherms (Figure 2, Figure 3) by BET method. Stair-form of capillary-condensation hysteresis loop, which is characteristic of mesoporous solids (IV isotherm type) proves the cylindrical non homogeneous form of pores as well as the presence of a few types of adsorption centers whose identification requires special analyses (IR-spectroscopy).

The value of specific surface area by BET was calculated from the equation:

$$
S_{s p}^{m}=a_{m} \omega_{m} N_{a}
$$

where $N_{a}$ is Avogadro's number, $\omega_{m}$-the area, occupied by one adsorbed molecule of gas on the surface, $\mathrm{m}^{2}, a_{m}$-monolayer capacity, $\mathrm{mol} \cdot \mathrm{g}^{-1}$.

The values of specific surface area of CNF was $132 \mathrm{~m}^{2} \cdot \mathrm{g}^{-1}$ (benzene vapor adsorption) and $128 \mathrm{~m}^{2} \cdot \mathrm{g}^{-1}$ (for acetic acid vapor). Error in the determination of the value of adsorption in terms of three measurements did not exceed 3\% - 5\%. Thus, specific surface area value of CNF on adsorption of benzene and acetic acid vapors decreased by $23 \%-24 \%$ compared with the specific surface area value of nitrogen adsorption. The reason behind this observable difference should be found most likely in the unavailability of micro pores for big molecules of the adsorptive.

Interpretation of adsorption of benzene and acetic acid vapor isotherms according to Dubinin and Radushkevich theory of pores volume filling [10] [11] aided to identify the parameters of two varieties of microporous structures of $\mathrm{CNF}$ ( $W_{01}, W_{02}$-adsorption surface pores; $B_{1}, B_{2}$-structural constant of pore 


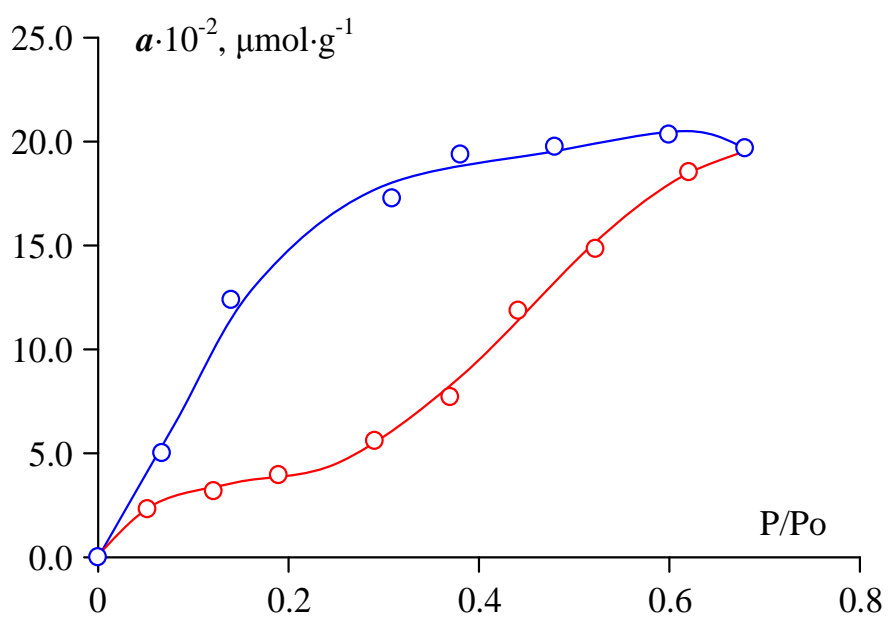

Figure 2. Adsorption-desorption isotherms of benzene vapor at $25^{\circ} \mathrm{C}$.

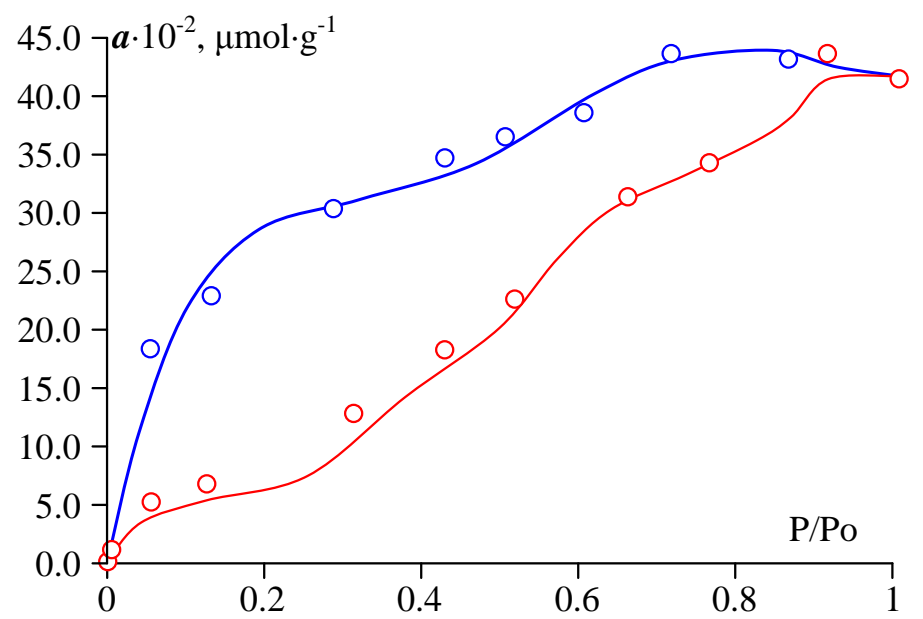

Figure 3. Adsorption-desorption Isotherms of acetic acid at $25^{\circ} \mathrm{C}$.

size), formed by small (index "1") and large (index "2") micropores (Table 2). Based on experimental isotherm of adsorption value corresponding to the initial point of hysteresis, volumes of micro- and mesopores filled with adsorbed substances were calculated.

The volume of macropores was calculated by the difference between the total and marginal adsorption volumes of pores. Total porosity $V_{\Sigma}$ was determined by the wetness of material which was equal to $0.804 \mathrm{~cm}^{3} \cdot \mathrm{g}^{-1}$ [12]. Marginal volume of pores was calculated from the maximum value of adsorption obtained from adsorption isotherm at a pressure close to saturated vapor.

The two sorbents (benzene and acetic acid) with different effective sizes of molecules gave satisfactorily corresponding values. High values of $B_{1}$ give evidence of these molecules adsorption in the mesopores with larger pore diameter.

The adsorption property of the carbon materials involved is strongly influenced by the materials temperature and exposure time as well as by the sequence of heat treatment-conditions: heat treatment-demetallization (method 1) or demetallization-heat treatment (method 2). 
Table 2. Characteristics of the porous structure of CNF.

\begin{tabular}{cccccccc}
\hline Adsorptive pairs & \multicolumn{2}{c}{ Pore volume $\mathrm{cm}^{3} \cdot \mathrm{g}^{-1}$} & \multicolumn{3}{c}{ Structural Characteristics } \\
\hline & Vm & Vme & Vma & $W_{01} \cdot 10^{2}$ & $W_{02} \cdot 10^{2}$ & $B_{1} \cdot 10^{6}$ & $B_{2} \cdot 10^{6}$ \\
\hline & & \multicolumn{7}{c}{$\mathrm{cm}^{3} \cdot \mathrm{g}^{-1}$} \\
\hline Benzene & 0.02 & 0.15 & 0.63 & 8.93 & 8.85 & 2.48 & 2.86 \\
Acetic acid & 0.03 & 0.2 & 0.56 & 5.6 & 5.4 & 1.1 & 3.7 \\
\hline
\end{tabular}

In order to select the conditions of modification of the initial CNF samples and to make up a mathematical method of the CM predetermined parameters the standard program Excel with the built-in data analysis package was used.

The change of the specific adsorption surface of CM related to the conditions of heat treatment process is adequately described by the polynomials (3) and (4);

For method I:

$$
y_{1}^{\mathrm{I}}=b_{0}+b_{1} x_{1}+b_{2} x_{1} x_{2}+b_{3} x_{1}^{2}+b_{4} x_{1}^{3}+b_{5} x_{1}^{4}
$$

For method II:

$$
y_{2}^{\mathrm{II}}=b_{0}+b_{1} x_{1}+b_{2} x_{1} x_{2}+b_{3} x_{1}^{2}+b_{4} x_{1}^{3}+b_{5} x_{1}^{2}
$$

where $x_{1}$ is the thermo-treatment process temperature ${ }^{\circ} \mathrm{C} ; x_{2}$ is the thermotreatment time in min., $b_{0}-b_{n}$ are coefficients.

The values of Fisher's criteria demonstrate the adequacy of the model, they being Fcalc $<$ F table;

The surfaces of the response functions, illustrating the effect of thermotreatment conditions on change of adsorption surface are shown in Figure 4.

The range of surface changes for samples obtained through method I and II lies between $90-346 \mathrm{~m}^{2} \cdot \mathrm{g}^{-1}$ and $173-254 \mathrm{~m}^{2} \cdot \mathrm{g}^{-1}$. The dependence of change of the specific surface area of carbon materials, measured by Nitrogen adsorption, on thermo-treatment, demonstrated an extreme character and reached maximum of $650^{\circ} \mathrm{C}$. The largest specific surface area for samples, obtained by method I was $\sim 346 \mathrm{~m}^{2} \cdot \mathrm{g}^{-1}$; while by method II $\sim 263 \mathrm{~m}^{2} \cdot \mathrm{g}^{-1}$. Comparison of the results shows that CM obtained by method I possess greater surface and have a wider range of values of specific surface area than material II obtained by method II.

The ability of carbon materials to adsorb hydrogen and carbon dioxide was studied by static volumetric method. The mathematical model given below adequately describes changes in adsorption ability of CM exposed to thermo-treatment as to hydrogen.

For method I

$$
y_{2}^{\mathrm{I}}=b_{0}+b_{1} x_{1}+b_{2} x_{1} x_{2}
$$

For method II

$$
\begin{gathered}
y_{2}^{\mathrm{II}}=b_{0}+b_{1} x_{1}+b_{2} x_{1} x_{2}+b_{3} x_{1}^{2} \\
F_{\text {calc }}^{\mathrm{I}}=1.983\left(F_{\text {tabl }}^{\mathrm{I}}=8.67\right), \quad F_{\text {calc }}^{\mathrm{II}}=1.098\left(F_{\text {Table }}^{\mathrm{II}}=8.654\right)
\end{gathered}
$$




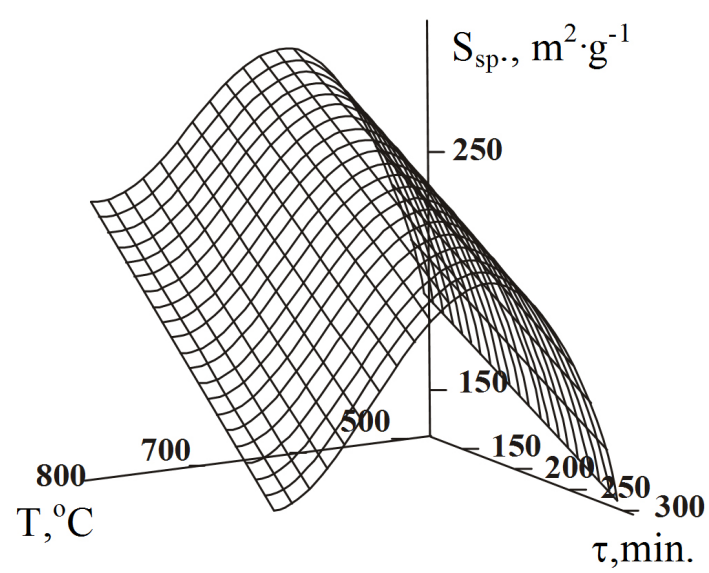

(a)

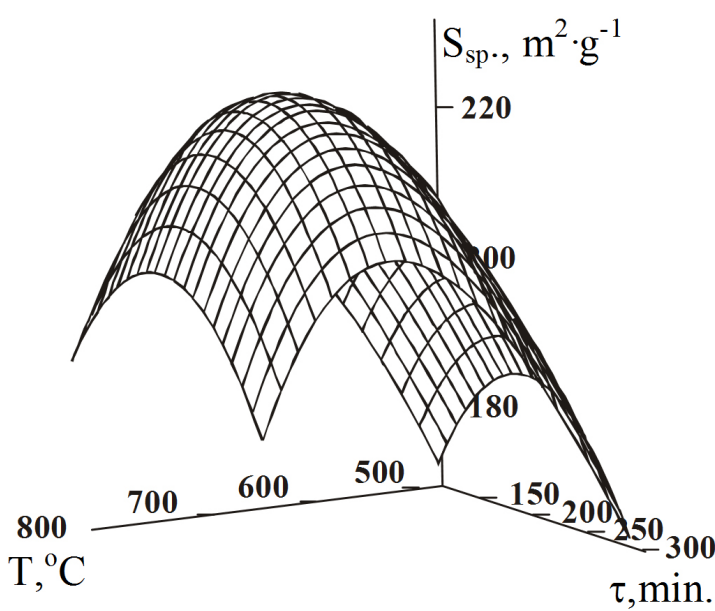

(b)

Figure 4. The effect of heat treatment conditions on change of the CM surface in terms of methods I (a) and II (b).

The surfaces constructed by these equations $y_{2}=\left(x_{1}, x_{2}\right)$ and effects of thermo-treating conditions on adsorption ability are presented in Figure 5. It is observed that the ability of carbon materials to adsorb hydrogen $(P=120 \mathrm{MPa})$ in samples obtained by method I is higher than in samples obtained by method II.

Depending on particular conditions of treatment and sequence of operations, adsorption capacity changed within the range of $3.6-5.5 \mathrm{mmol} \cdot \mathrm{g}^{-1}$ (method I) and $3.4-4.5 \mathrm{mmol} \cdot \mathrm{g}^{-1}$ (method II). It should be noted that irreversible adsorption value reached accordingly $3.2-20.7$ and $11.9 \%-38.6 \%$ as to the initial one.

Analysis of data on adsorption of CF leads to the conclusion that the ability of FC to adsorb hydrogen was due to the degree of graphitization, rather than to the adsorption surface, that is the more graphitized materials are the higher the adsorption capacity. Besides, the less graphitized the materials, the greater the degree of adsorption irreversibility.

Data representing the ability of carbon materials to adsorb $\mathrm{CO}_{2}$ are represented in Table 3 demonstrating as well the relationship between the 
Table 3. The ability of carbon materials to adsorb $\mathrm{CO}_{2}$.

\begin{tabular}{|c|c|c|c|c|c|c|}
\hline \multirow[t]{2}{*}{$\begin{array}{l}\text { Sample } \\
\text { No. }\end{array}$} & \multirow[t]{2}{*}{ Sorbent } & \multirow{2}{*}{$\begin{array}{c}\begin{array}{c}\text { Specific } \\
\text { surface area }\end{array} \\
\mathrm{M}^{2} \cdot \mathrm{g}^{-1} \\
(\text { on } \mathrm{N} 2)\end{array}$} & \multirow[t]{2}{*}{$\begin{array}{c}\text { Pressure, } \\
\text { Mpa }\end{array}$} & \multirow{2}{*}{$\begin{array}{c}\text { Sorption capacity } \\
\mathrm{mmol} \cdot \mathrm{g}^{-1}\end{array}$} & \multicolumn{2}{|c|}{ Irreversible adsorption } \\
\hline & & & & & $\mathrm{mmol} \cdot \mathrm{g}^{-1}$ & $\%$ of initial \\
\hline \multirow[t]{3}{*}{1} & $\begin{array}{l}\text { Demetallized } \\
\text { CNF }\end{array}$ & 173 & 0.12 & 0.116 & 0.075 & 64.2 \\
\hline & & & 0.51 & 0.284 & 0.131 & 46.2 \\
\hline & & & 1.03 & 0.58 & 0.175 & 30.1 \\
\hline \multirow[t]{3}{*}{2} & DTCNF & 236 & 0.11 & 0.18 & 0.053 & 29.4 \\
\hline & (method I) & & 0.53 & 0.508 & 0.134 & 26.3 \\
\hline & & & 1.06 & 0.761 & 0.239 & 31.4 \\
\hline \multirow[t]{3}{*}{3} & TDCNF & 346 & 0.11 & 0.28 & 0.036 & 12.7 \\
\hline & (method II) & & 0.52 & 1.438 & 0.145 & 10.1 \\
\hline & & & 1.05 & 1.58 & 0.32 & 20.2 \\
\hline \multirow[t]{3}{*}{4} & Carbon grade A & 690 & 0.12 & 1.294 & 0.561 & 43.3 \\
\hline & & & 0.58 & 3.509 & 1.36 & 38.9 \\
\hline & & & 1.01 & 4.214 & 1.813 & 43 \\
\hline \multirow[t]{3}{*}{5} & Sibunite & 350 & 0.11 & 0.179 & 0.018 & 9.9 \\
\hline & & & 0.51 & 0.696 & 0.054 & 7.7 \\
\hline & & & 1 & 0.973 & 0.128 & 13.1 \\
\hline \multirow[t]{3}{*}{6} & Silica gel & 333 & 0.12 & 0.494 & 0.011 & 2.2 \\
\hline & & & 0.51 & 0.919 & 0.049 & 5.3 \\
\hline & & & 1.03 & 1.357 & 0.138 & 10.2 \\
\hline \multirow[t]{3}{*}{7} & Aluminum oxide & 260 & 0.1 & 0.366 & 0.058 & 15.8 \\
\hline & & & 0.51 & 0.804 & 0.174 & 21.4 \\
\hline & & & 1.02 & 1.379 & 0.268 & 19.4 \\
\hline
\end{tabular}

degree of graphitization of samples and irreversible adsorption. Sample 3, obtained by method I at $\mathrm{T} 650^{\circ}$ and heat treatment time of 120 minutes, differs from samples 1 and 2 in having a higher degree of graphitization and possessing a higher adsorption capacity as to $\mathrm{CO}_{2}$. Adsorption capacity for $\mathrm{CO}_{2}$ of sample 2 obtained by method II under the same conditions of processing is two times lower. Sample 1(not graphitized) chemosorbs $\mathrm{CO}_{2}$ in a greater degree than samples 2 and 3. Direct adsorption manifested itself better on less graphitized samples and the irreversible one on more graphitized samples. For samples $1-3$ it is traced a relationship between specific adsorption surface and adsorption ability: the higher the specific surface area, the higher the adsorption ability of the material of given series. Comparison of sample 3 with conventional adsorbents (Table 3) showed that given $\mathrm{CM}$ displays a higher adsorption capacity for $\mathrm{CO}_{2}$ than the latter ones (except carbon A brand). 


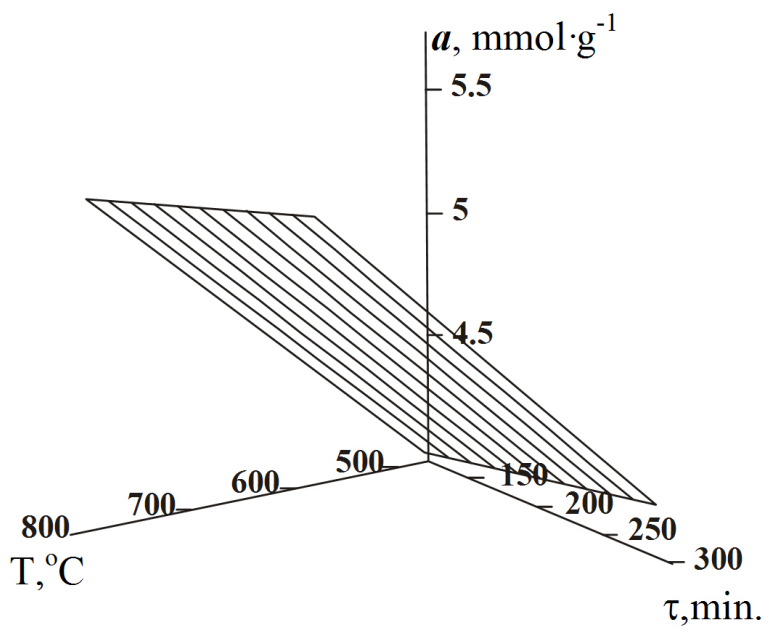

(a)

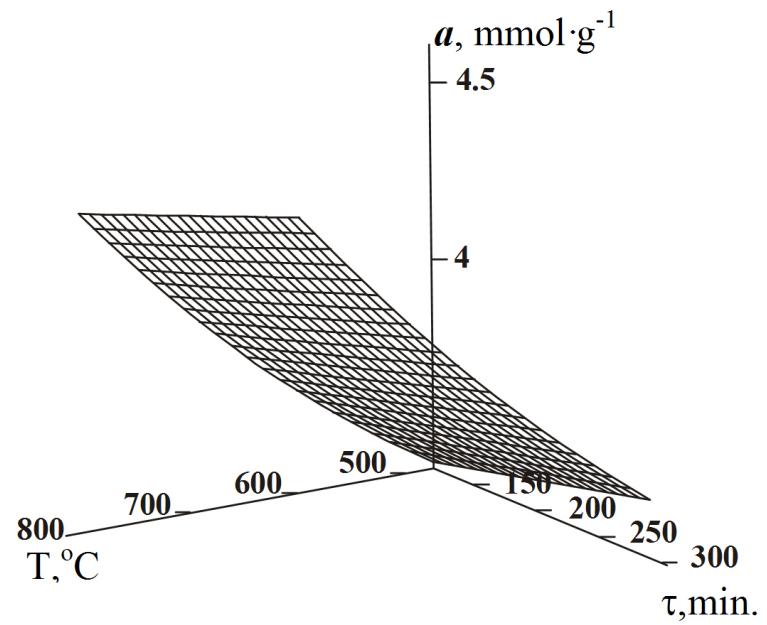

(b)

Figure 5. Samples of CNF obtained by methods I (a), II (b). Effect of thermo-treatment conditions on the change of adsorption capacity as to $\mathrm{H}_{2}$.

\section{Conclusion}

Thus, the results of present CM research demonstrate the possibility of producing from $\mathrm{CF}$ a wide range of carbon adsorbents varying the conditions of their subsequent processing. The possibility of obtaining highly porous CM from CNF with predetermined characteristics may well be of interest in considering them as adsorbents and catalytic supports.

\section{Funding}

Contribution supported by Ministry of Education and Science grant (RFMEFI58015X0004)

\section{References}

[1] Kuvshinov, G.G., Mogilnykh, Yu. I., Kuvshinov, D.G., Zaikovskii, V.I. and Avdeeva, L.B. (1998) Adsorption Method in the Investigation of the Characteristics of Acti- 
vated Carbons Based on Anthracite. Carbon, 36, c.87.

[2] Bong, H.K. and Alexandrov, V.V. (1998) Technology Characteristics of Carbon Sorbents and Supported Catalysts Based on the Mineral Starting Materials. Izvestiya USSR Academy of Sciences, Institute of Coal, Kharkov, 2, 35-47.

[3] Dilloin, A.C., Jones, K.M. and Bekkedahl, T.A. (1997) Influence of Anthracite Pretreatment in the Preparation of Activated Carbons. Nature, 386, 377-379.

[4] Rodriguez, N.M. and Baker, R.T.K. (1997) Storage of Hydrogen in Layered Nanostructures. US Patent № 5653951.

[5] Lyubchik, S.B., Benoit, R. and Beguin, F. (2002) Influence of Chemical Modification of Anthracite on the Porosity of the Resulting Activated Carbons. Carbon, 40, 1287-1294.

[6] Bratek, K., Bratek, W., Gerus-Piasecka, I., Jasienko, S. and Wilk, P. (2002) Properties and Structure of Diferent Rank Anthracites. Fuel, 81, 97-108. https://doi.org/10.1016/S0016-2361(01)00120-X

[7] Marsh, H. and Rodriguez-Reinoso, F. (2006) Activated Carbon. Elsevier Science \& Technology Books, $536 \mathrm{p}$.

[8] Darmanin, T. and Guittard, F. (2014) Engineering of Biobased Nanostructured Interfaces: Properties and Applications. Journal of Materials Chemistry A, 2, 1631916359.

[9] Darmanin, T. and Guittard, F. (2015) Superhydrophobic and Superoleophobic Nanostructured Conducting Polymer Films: From Nanofibers to Nanotubes. Advanced Materials Interfaces, 2, 1500081/1-1500081/7.

[10] Ramos Chagas, G., Darmanin, T. and Guittard, F. (2015) Hydrophobicity and Water Adhesion from Nanotubes to Nanospheres of Structured Polymeric Surfaces. The Beilstein Journal of Nanotechnology, 6, 2078-2087.

[11] Darmanin, T. and Guittard, F. (2016) Engineering of Biobased Nanostructured Interfaces: Properties and Application. Journal of Materials Chemistry A.

[12] Bong, H.K., Temkin, O.N., Binh, H.H. and Yamandiy, D.I. (2011) Porous Structure, Salt Component Distribution and Catalytic Preference of Zinc Acetate Catalysts for Vinylacetate Synthesis on Modified Carbon Supports. Journal of Chemistry and Chemical Engineering (USA), 5, 473-477. 